\title{
Application of Dijkstra Algorithm to Proposed Tramway of a Potential World Class University
}

\author{
M. C. Agarana1, N. C. Omoregbe², M. O. Ogunpeju² \\ ${ }^{1}$ Department of Mathematics, Covenant University, Ota, Nigeria \\ ${ }^{2}$ Department of Computer and Information Science, Covenant University, Ota, Nigeria \\ Email: michael.agarana@covenantuniversity.edu.ng
}

Received 30 December 2016; accepted 21 March 2016; published 24 March 2016

Copyright (C) 2016 by authors and Scientific Research Publishing Inc.

This work is licensed under the Creative Commons Attribution International License (CC BY). http://creativecommons.org/licenses/by/4.0/

(c) (i) Open Access

\begin{abstract}
Nowadays, the development of "smart cities" with a high level of quality of life is becoming a prior challenge to be addressed. In this paper, promoting the model shift in railway transportation using tram network towards more reliable, greener and in general more sustainable transportation modes in a potential world class university is proposed. "Smart mobility" in a smart city will significantly contribute to achieving the goal of a university becoming a world class university. In order to have a regular and reliable rail system on campus, we optimize the route among major stations on campus, using shortest path problem Dijkstra algorithm in conjunction with a computer software called LINDO to arrive at the optimal route. In particular, it is observed that the shortest path from the main entrance gate (Canaan land entrance gate) to the Electrical Engineering Department is of distance $0.805 \mathrm{~km}$.
\end{abstract}

\section{Keywords}

Potential World Class University, Optimization, Dijkstra Algorithm, Shortest Path, Tramway

\section{Introduction}

One of the major advantages of rail transit, particularly Trams, is that it can provide a highly efficient and very attractive mode of public transit to provide access to and from hostels and places on university campuses [1]. Rail is ideally suited to accommodate the surges of passenger volumes that are often associated with University main activity centres [2]-[4]. Most campuses in sub Saharan Africa are served by heavily fossil fuel dependent automobiles (such as busses, cars, motorcycles and tricycles). A tram system is a rail-based transit system that runs 
mainly or completely along streets (i.e. with street running), with relatively low capacity and frequent stops [5] [6]. A tram (also known as tramcar; and in North America known as streetcar, trolley or trolley car), is a rail vehicle which runs on tracks along public urban streets (called street running) [1] [7]. Tram network is presently in existence in Melbourne University, Australia. The Melbourne tramway network is a major form of public transport in Melbourne, the capital city of the state of Victoria, Australia [2]. As at May 2014, the network consisted of 250 kilometres of track, 493 trams, 25 routes, and 1763 tram stops. It is the largest urban tramway network in the world, ahead of the networks in St. Petersburg (205 km), Berlin (190 km), Moscow (181 km) and Vienna $(172 \mathrm{~km})$ [2] [6]. Members of the university community have to travel from one point to another on campus for different reasons, ranging from attending lectures to attending meetings. In order to travel and arrive at destinations in good times, movement path has to be chosen wisely. This is an example of shortest path problem and the weight will be the time cost. Certainly different routes will involve different stations and pathways [8] [9]. For this paper, we assume that the tram network will cover only the following spots on covenant university campus, which represent the stations, in Table 1 . We also assume that the average speed on campus is $50 \mathrm{~km} / \mathrm{h}$, and that the time cost is always directly proportional to the distance covered. Table 2 shows the initial distance between two given spots (stations) on campus. Figure 1, on the other hand, shows the directed weighted graph showing the network of the proposed rail paths, with the edges as the initial distance between two given stations. The network, formed using Table 2, is to be optimized, by finding the shortest path from station A (Canaan land entrance gate), which is our starting node, to station $\mathrm{U}$ (Electrical Engineering department), which is our target node. Dijkstra algorithm is applied on the network in Figure 1 to find the shortest distance from node A

Table 1. Proposed rail stations on camp.

\begin{tabular}{|c|c|c|}
\hline $\mathrm{S} / \mathrm{N}$ & Notation & Proposed stations \\
\hline 1 & A & CANAAN LAND ENTRANCE \\
\hline 2 & $\mathrm{~B}$ & CANAAN RESTAURANT \\
\hline 3 & $\mathrm{C}$ & DOMINION Book STORE \\
\hline 4 & $\mathrm{D}$ & COVENANT UNIVERSITY GATE \\
\hline 5 & $\mathrm{E}$ & CU MAIN ROUND ABOUT \\
\hline 6 & $\mathrm{~F}$ & CHAPEL PARKING LOT \\
\hline 7 & G & EAGLE SQUARE(HOSTEL) \\
\hline 8 & $\mathrm{H}$ & CFMB \\
\hline 9 & I & WORD OF FAITH BIBLE INSTITUTE \\
\hline 10 & $\mathrm{~J}$ & GREEN PASTURE \\
\hline 11 & K & ALDC \\
\hline 12 & $\mathrm{~L}$ & CU CENTRE FOR LEANING AND RESEARCH \\
\hline 13 & M & STAFF QUARTERS(FAITH AVENUE) \\
\hline 14 & $\mathrm{~N}$ & GUEST HOUSE \\
\hline 15 & $\mathrm{O}$ & CAMP HOUSE \\
\hline 16 & $\mathrm{P}$ & MECHANCIAL ENGINEERING \\
\hline 17 & Q & CENTRE FOR DEVELOPMENT STUDIES \\
\hline 18 & $\mathrm{R}$ & CAFE 2 \\
\hline 19 & S & CIVIL ENGINEERING \\
\hline 20 & $\mathrm{~T}$ & YOUTH CHAPEL \\
\hline 21 & $\mathrm{U}$ & ELECTRRICAL ENGINEERING DEPARTMENT \\
\hline
\end{tabular}




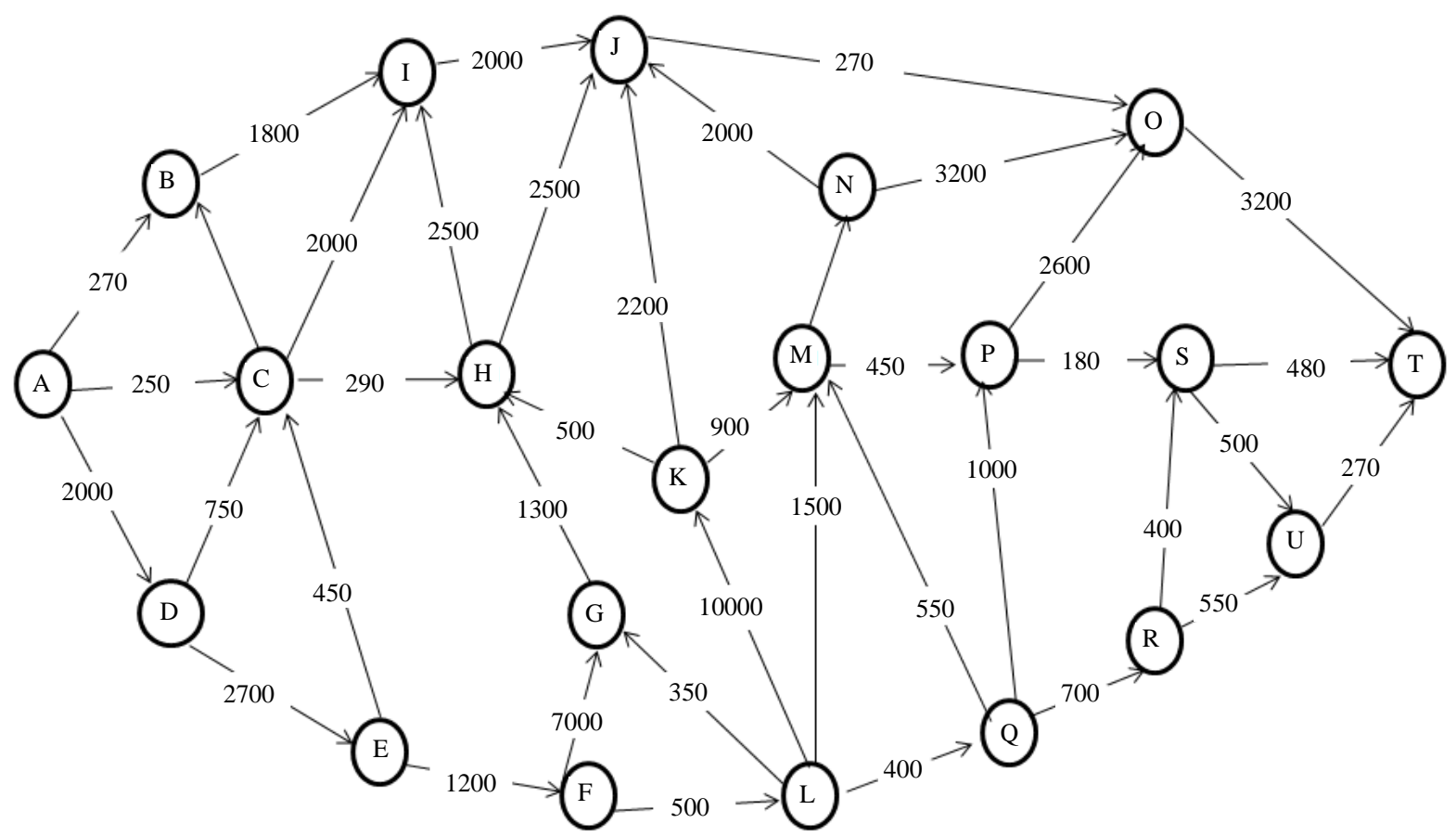

Figure 1. Directed graph showing the distances between the nodes.

to node. The main advantage of this work is the fact that a simple algorithm, such as Dijkstra algorithm, can be applied, with some assumptions, to estimate the shortest part of a proposed tramway in a potential world class university. Tramway transit system is very new in universities in sub-Saharan Africa countries. Tram system will soon be the transit mode of choice among many sub-Saharan Universities of lower to medium population density. Tram systems are very safe in pedestrian environments $\sim$ far safer than automobiles—while providing convenient surface access to the public. Some of the advantages of this would be lower cost and greater flexibility, reduction in carbon dioxide emission and convenience, especially during rainy season. Also, the following are other benefits of this transportation system; extension of rail network to areas currently not served by campus shuttle cars, reduction in cost of transportation within the covenant university, reduction in carbon monoxide in the air, making the university cleaner and always quite, making the university accessible and socially vibrant [2] [6] [9]. Dijkstra's algorithm is an algorithm for finding the shortest paths between nodes in a graph, which may represent, for example, road networks [9] [10]. The algorithm exists in many variants; Dijkstra's original variant found the shortest path between two nodes, but a more common variant fixes a single node as the "source" node and finds shortest paths from the source to all other nodes in the graph, producing a shortest path tree [4] [10]. Dijkstra Algorithm was made popular by Edger Wybe Dijkstra, a Dutch computer scientist from Netherland. He was known for his many essays on programming. The object of this paper therefore, is to present an optimisation model [3] [9] [10], which deals with the selection of the routes on which services will be offered using TRAM system in Covenant University [6] [11] [12]. This study exposes the need for a Tram transportation system on campus with expanded rail network to meet the growing needs of the university as regards mobility. It is also intended to know how to move from one point to another in a potential world class university, in order to save time and reduce cost [13] [14]. This is a single source shortest path problem [10] [11]. Dijkstra Algorithm is used to find solution to this problem. The following conditions are assumed in this paper: the graph in Figure 1 is directed, all edges have non-negative weights, and the graph is also connected. Figure 2 shows a Tram in motion [8] [12]. The shortest path obtained in the work, represents route to be taken in order to optimize the proposed tramway [5] [7].

\section{Formulation of Problem}

The Data collected are shown in Table 1 and Table 2. The weighted directed graph is drawn using the information from the tables. 
Table 2. Distance between two locations/stations (x10).

\begin{tabular}{|c|c|c|}
\hline $\mathrm{S} / \mathbf{N}$ & ROUTES & Distance between two points (in meters) x10 \\
\hline 1 & A---C & 250 \\
\hline 2 & A---B & 270 \\
\hline 3 & A---D & 2000 \\
\hline 4 & B---C & 1800 \\
\hline 5 & B---I & 1800 \\
\hline 6 & D---C & 750 \\
\hline 7 & D---E & 2700 \\
\hline 8 & C---I & 2000 \\
\hline 9 & C---H & 290 \\
\hline 10 & E---C & 450 \\
\hline 11 & E---F & 1200 \\
\hline 12 & G---H & 1300 \\
\hline 13 & F---C & 500 \\
\hline 14 & F---G & 7000 \\
\hline 15 & $\mathrm{H}---\mathrm{K}$ & 500 \\
\hline 16 & H---J & 2500 \\
\hline 17 & H---1 & 2500 \\
\hline 18 & I---J & 2000 \\
\hline 19 & J---O & 220 \\
\hline 20 & K---J & 2200 \\
\hline 21 & K---M & 900 \\
\hline 22 & L---M & 1500 \\
\hline 23 & L---K & 10000 \\
\hline 24 & L---G & 350 \\
\hline 25 & L---Q & 400 \\
\hline 26 & M---N & 300 \\
\hline 27 & M---P & 450 \\
\hline 28 & N---O & 3200 \\
\hline 29 & N---J & 2000 \\
\hline 30 & O---T & 3200 \\
\hline 31 & J---O & 270 \\
\hline 32 & P---O & 2600 \\
\hline 33 & P---S & 150 \\
\hline 34 & Q---R & 700 \\
\hline 35 & Q---P & 1000 \\
\hline 36 & Q---M & 550 \\
\hline 37 & R---S & 400 \\
\hline 38 & R---U & 550 \\
\hline 39 & S---T & 450 \\
\hline 40 & S---U & 500 \\
\hline 41 & T---U & 270 \\
\hline
\end{tabular}




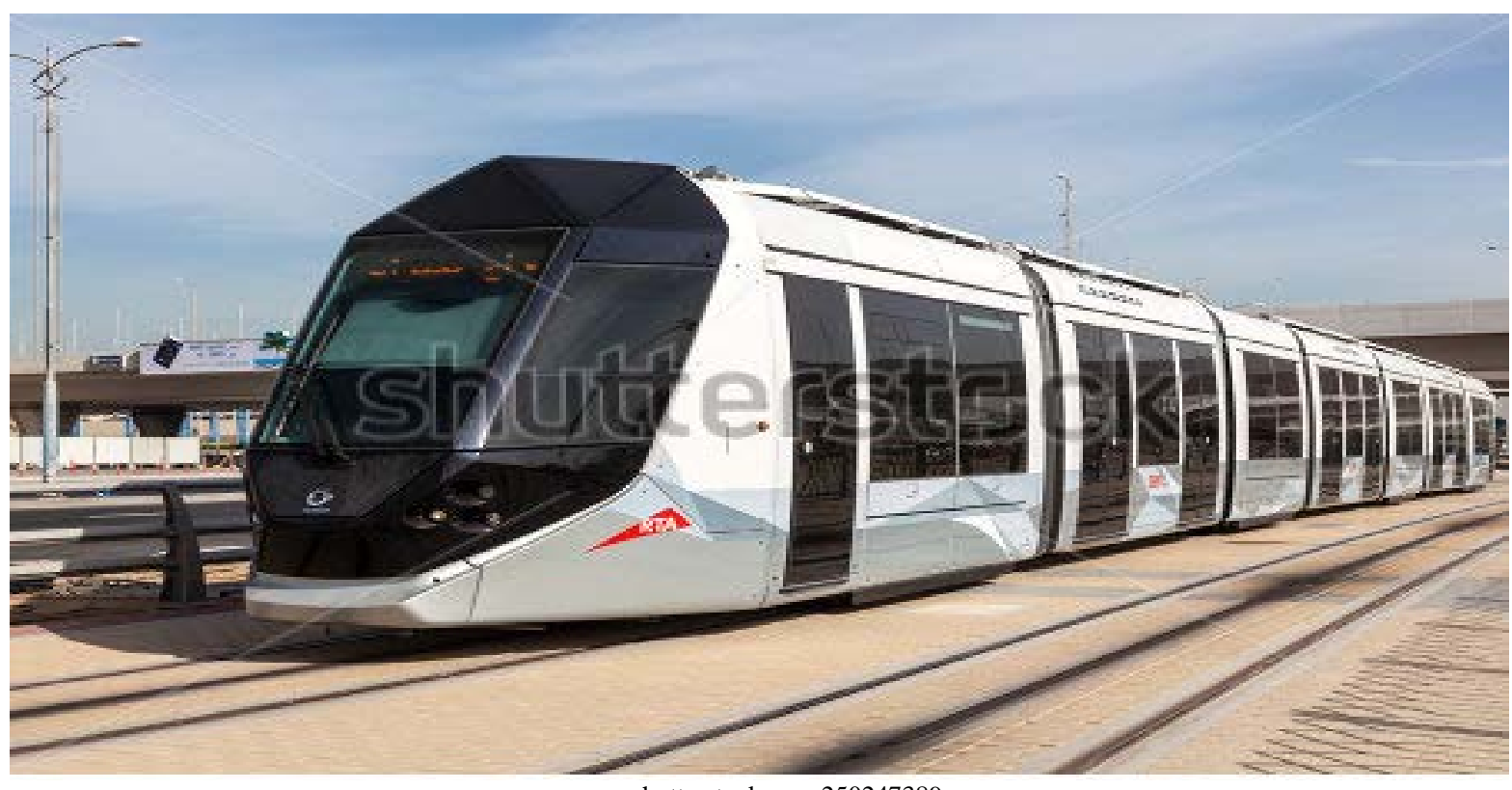

www.shutterstock.com 250247389

Figure 2. A TRAM in motion (Source: www.shutterstock.com/s/tram/sear.html).

\section{Assumptions}

The following assumptions are claimed in this work:

1) There is no waiting time at the stations.

2) The shortest distance in this work means shortest time costing.

3) One-way travel condition is considered.

\section{Problem Solution}

\subsection{How Dijkstra Algorithm Works}

Dijkstra's algorithm gives shortest distance between a source vertex and a target vertex in a weighted graph. Let the node at which we are starting be called the initial node (node A). Let the distance of node B be the distance from the initial node A to B. Dijkstra's algorithm will assign some initial distance values and will try to improve them step by step. The procedure is as follows (Nilesh More, 2014):

1) Assign to every node a tentative distance value: set it to zero for our initial node and to infinity for all other nodes.

2) Set the initial node as current. Mark all other nodes unvisited. Create a set of all the unvisited nodes called the unvisited set.

3) For the current node, consider all of its unvisited neighbors and calculate their tentative distances. Compare the newly calculated tentative distance to the current assigned value and assign the smaller one. For example, if the current node $\mathrm{A}$ is marked with a distance of 5 , and the edge connecting it with a neighbour $\mathrm{B}$ has length 4 , then the distance to B (through A) will be $5+4=9$. If B was previously marked with a distance greater than 9 then change it to 9 . Otherwise, keep the current value.

4) When we are done considering all of the neighbors of the current node, mark the current node as visited and remove it from the unvisited set. A visited node will never be checked again.

5) If the destination node has been marked visited (when planning a route between two specific nodes) or if the smallest tentative distance among the nodes in the unvisited set is infinity (when planning a complete traversal; occurs when there is no connection between the initial node and remaining unvisited nodes), then stop. The algorithm has finished.

6) Otherwise, select the unvisited node that is marked with the smallest tentative distance, set it as the new "current node", and go back to Step 3. 


\subsection{Application of the Dijkstra Algorithm to Our Problem}

Let node A be the initial node. Let the distance between the nodes be as shown in Figure 1. In order to improve on these initial distances we will try to improve on them step by step, using the Dijkstra's algorithm procedure as explained in Section 3.1. This resulted in Table 3 below.

\section{Result Discussion}

Table 3 shows the result of the application of Dijkstra's algorithm to the weighted graph in Figure 1 . It can be deduced from this table that the required shortest path from the initial node A to the target node $\mathrm{U}$ is as follows:

$$
\mathrm{A} \rightarrow \mathrm{D} \rightarrow \mathrm{E} \rightarrow \mathrm{F} \rightarrow \mathrm{L} \rightarrow \mathrm{Q} \rightarrow \mathrm{R} \rightarrow \mathrm{U}
$$

By interpretation, starting from Canaan land entrance gate, the rail path should go through Covenant University gate, then pass through CU main round about, then the Chapel parking lot, then CU Centre for learning and research, then through the centre for development studies, then finally through café 2 to the Electrical Engineering department.

From Table 3, it can be shown that the minimum distance from node A to node $\mathrm{U}$ is 805 meters as shown below:

Table 3. The matrix of distances between stations resulting from application of Dijkstra algorithm.

\begin{tabular}{|c|c|c|c|c|c|c|c|c|c|c|c|c|c|c|c|c|c|c|c|}
\hline B & C & D & $\mathbf{E}$ & $\mathbf{F}$ & G & $\mathbf{H}$ & I & $\mathbf{J}$ & $\mathbf{K}$ & $\mathbf{L}$ & $\mathbf{M}$ & $\mathbf{N}$ & $\mathbf{O}$ & $\mathbf{P}$ & $\mathbf{Q}$ & $\mathbf{R}$ & $\mathrm{S}$ & $\mathbf{T}$ & $\mathbf{U}$ \\
\hline A $270_{\mathrm{A}}$ & $250_{\mathrm{A}}$ & $2000_{\mathrm{A}}$ & $\infty$ & $\infty$ & $\infty$ & $\infty$ & $\infty$ & $\infty$ & $\infty$ & $\infty$ & $\infty$ & $\infty$ & $\infty$ & $\infty$ & $\infty$ & $\infty$ & $\infty$ & $\infty$ & $\infty$ \\
\hline C $270_{\mathrm{A}}$ & $250_{\mathrm{A}}$ & $2000_{\mathrm{A}}$ & $\infty$ & $\infty$ & $\infty$ & $540_{\mathrm{C}}$ & $2250_{\mathrm{C}}$ & $\infty$ & $\infty$ & $\infty$ & $\infty$ & $\infty$ & $\infty$ & $\infty$ & $\infty$ & $\infty$ & $\infty$ & $\infty$ & $\infty$ \\
\hline B $270_{A}$ & & $2000_{\mathrm{A}}$ & $\infty$ & $\infty$ & $\infty$ & $540_{\mathrm{C}}$ & $2070_{B}$ & $\infty$ & $\infty$ & $\infty$ & $\infty$ & $\infty$ & $\infty$ & $\infty$ & $\infty$ & $\infty$ & $\infty$ & $\infty$ & $\infty$ \\
\hline D & & $2000_{\mathrm{A}}$ & $4700_{\mathrm{D}}$ & $\infty$ & $\infty$ & & $2070_{\mathrm{B}}$ & $3040_{\mathrm{H}}$ & $\infty$ & $\infty$ & $\infty$ & $\infty$ & $\infty$ & $\infty$ & $\infty$ & $\infty$ & $\infty$ & $\infty$ & $\infty$ \\
\hline I & & & $4700_{\mathrm{D}}$ & $\infty$ & $\infty$ & & $2070_{\mathrm{B}}$ & $3040_{\mathrm{H}}$ & $\infty$ & $\infty$ & $\infty$ & $\infty$ & $\infty$ & $\infty$ & $\infty$ & $\infty$ & $\infty$ & $\infty$ & $\infty$ \\
\hline $\mathbf{J}$ & & & $4700_{\mathrm{D}}$ & $\infty$ & $\infty$ & & & $3040_{\mathrm{H}}$ & $\infty$ & $\infty$ & $\infty$ & $\infty$ & $3310_{\mathrm{J}}$ & $\infty$ & $\infty$ & $\infty$ & $\infty$ & $\infty$ & $\infty$ \\
\hline $\mathbf{O}$ & & & $4700_{\mathrm{D}}$ & $\infty$ & $\infty$ & & & & $\infty$ & $\infty$ & $\infty$ & $\infty$ & $3310_{\mathrm{J}}$ & $\infty$ & $\infty$ & $\infty$ & $\infty$ & $6500_{\mathrm{O}}$ & $\infty$ \\
\hline $\mathbf{E}$ & & & $4700_{\mathrm{D}}$ & $5900_{\mathrm{E}}$ & $\infty$ & & & & $\infty$ & $\infty$ & $\infty$ & $\infty$ & & $\infty$ & $\infty$ & $\infty$ & $\infty$ & $6500_{\mathrm{O}}$ & $\infty$ \\
\hline $\mathbf{F}$ & & & & $5900_{\mathrm{E}}$ & $12900_{\mathrm{F}}$ & & & & $\infty$ & $6400_{\mathrm{F}}$ & $\infty$ & $\infty$ & & $\infty$ & $\infty$ & $\infty$ & $\infty$ & $6500_{\mathrm{O}}$ & $\infty$ \\
\hline $\mathbf{T}$ & & & & & $12900_{\mathrm{F}}$ & & & & $\infty$ & $6400_{\mathrm{F}}$ & $\infty$ & $\infty$ & & $\infty$ & $\infty$ & $\infty$ & $\infty$ & $6500_{\mathrm{O}}$ & $\infty$ \\
\hline $\mathbf{L}$ & & & & & $6750_{\mathrm{L}}$ & & & & $16400_{\mathrm{L}}$ & $6400_{\mathrm{F}}$ & $7900_{\mathrm{L}}$ & $\infty$ & & $\infty$ & $6800_{\mathrm{L}}$ & $\infty$ & $\infty$ & & $\infty$ \\
\hline G & & & & & $6750_{\mathrm{L}}$ & & & & $16400_{\mathrm{L}}$ & & $7900_{\mathrm{L}}$ & $\infty$ & & $\infty$ & $6800_{\mathrm{L}}$ & $\infty$ & $\infty$ & & $\infty$ \\
\hline $\mathbf{Q}$ & & & & & & & & & $16400_{\mathrm{L}}$ & & $7350_{\mathrm{Q}}$ & $\infty$ & & $7800_{\mathrm{Q}}$ & $6800_{\mathrm{L}}$ & $7500_{\mathrm{Q}}$ & $\infty$ & & $\infty$ \\
\hline $\mathbf{M}$ & & & & & & & & & $16400_{\mathrm{L}}$ & & $7350_{\mathrm{Q}}$ & $7650_{M}$ & & $7800_{M}$ & & $7500_{\mathrm{Q}}$ & $\infty$ & & $\infty$ \\
\hline $\mathbf{R}$ & & & & & & & & & $16400_{\mathrm{L}}$ & & & $7650_{M}$ & & $7800_{M}$ & & $7500_{\mathrm{Q}}$ & $7900_{\mathrm{R}}$ & & $8150_{R}$ \\
\hline $\mathbf{P}$ & & & & & & & & & $16400_{\mathrm{L}}$ & & & & & $7800_{M}$ & & & $7900_{R}$ & & $8150_{R}$ \\
\hline $\mathbf{S}$ & & & & & & & & & $16400_{\mathrm{L}}$ & & & & & & & & $7900_{R}$ & & $8150_{R}$ \\
\hline $\mathbf{U}$ & & & & & & & & & $16400_{\mathrm{L}}$ & & & & & & & & & & \\
\hline $\mathbf{K}$ & & & & & & & & & $16400_{\mathrm{L}}$ & & & & & & & & & & \\
\hline
\end{tabular}




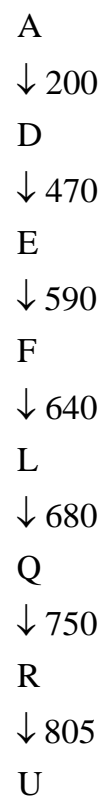

The actual shortest distance, therefore, is 805 meters. That is $0.805 \mathrm{~km}$ from Canaan land entrance gate to the Electrical Engineering department. From Table 3, we can show the shortest distance between nodes from the initial node A, from where the above shortest distance is derived, as follows:

$$
\begin{aligned}
& A \rightarrow\left\{\begin{array}{c}
25 \rightarrow C \\
200 \rightarrow D \\
27 \rightarrow B
\end{array}\right. \\
& \mathrm{B} \rightarrow 207 \rightarrow \mathrm{I} \\
& \mathrm{C} \rightarrow 54 \rightarrow \mathrm{H} \\
& \mathrm{D} \rightarrow 470 \rightarrow \mathrm{E} \\
& \mathrm{E} \rightarrow 590 \rightarrow \mathrm{F} \\
& \mathrm{F} \rightarrow 640 \rightarrow \mathrm{L} \\
& \mathrm{H} \rightarrow 304 \rightarrow \mathrm{J} \\
& \mathrm{J} \rightarrow 331 \rightarrow \mathrm{O} \\
& \mathrm{K} \rightarrow 790 \rightarrow \mathrm{S} \\
& \mathrm{L} \rightarrow\left\{\begin{array}{c}
680 \rightarrow \mathrm{Q} \\
675 \rightarrow \mathrm{G} \\
1640 \rightarrow \mathrm{K}
\end{array}\right. \\
& \mathrm{M} \rightarrow\left\{\begin{array}{l}
780 \rightarrow \mathrm{P} \\
765 \rightarrow \mathrm{O}
\end{array}\right. \\
& \mathrm{O} \rightarrow 651 \rightarrow \mathrm{T} \\
& \mathrm{Q} \rightarrow\left\{\begin{array}{l}
735 \rightarrow \mathrm{M} \\
750 \rightarrow \mathrm{R}
\end{array}\right. \\
& \mathrm{R} \rightarrow 805 \rightarrow \mathrm{U}
\end{aligned}
$$

From (3) above, the initial distance between the starting node A to C, D and B are $25 \mathrm{~m}, 200 \mathrm{~m}$ and $27 \mathrm{~m}$ respectively. 
From (4): the shortest distance of I from A is $207 \mathrm{~m}$ and it is through B.

From (5): the shortest distance of $\mathrm{H}$ from $\mathrm{A}$ is $54 \mathrm{~m}$ and it is through $\mathrm{C}$.

From (6): the shortest distance of $\mathrm{E}$ from $\mathrm{A}$ is $470 \mathrm{~m}$ and it is through D.

From (7): the shortest distance of $F$ from $A$ is $470 \mathrm{~m}$ and it is through $\mathrm{E}$.

From (8): the shortest distance of $\mathrm{L}$ from $\mathrm{A}$ is $470 \mathrm{~m}$ and it is through $\mathrm{F}$.

From (9): the shortest distance of $\mathrm{J}$ from $\mathrm{A}$ is $470 \mathrm{~m}$ and it is through $\mathrm{H}$.

From (10): the shortest distance of $\mathrm{O}$ from $\mathrm{A}$ is $470 \mathrm{~m}$ and it is through $\mathrm{J}$.

From (11): the shortest distance of $\mathrm{S}$ from $\mathrm{A}$ is $470 \mathrm{~m}$ and it is through $\mathrm{K}$.

From (12): the shortest distance of Q from A is $680 \mathrm{~m}$ and it is through $\mathrm{L}$, the shortest distance of $\mathrm{G}$ from $\mathrm{A}$ is $675 \mathrm{~m}$ and it is through $\mathrm{L}$. the shortest distance of $\mathrm{K}$ from $\mathrm{A}$ is $1640 \mathrm{~m}$ and it is through $\mathrm{L}$.

From (13): the shortest distance of $\mathrm{P}$ from $\mathrm{A}$ is $780 \mathrm{~m}$ and it is through $\mathrm{M}$ the shortest distance of $\mathrm{O}$ from $\mathrm{A}$ is $765 \mathrm{~m}$ and it is through $\mathrm{M}$.

From (14): the shortest distance of $\mathrm{T}$ from $\mathrm{A}$ is $651 \mathrm{~m}$ and it is through $\mathrm{O}$.

From (15): the shortest distance of $\mathrm{M}$ from $\mathrm{A}$ is $735 \mathrm{~m}$ and it is through $\mathrm{Q}$ the shortest distance of $\mathrm{R}$ from $\mathrm{A}$ is $750 \mathrm{~m}$ and it is through Q.

From (16):the shortest distance of $\mathrm{U}$ from $\mathrm{A}$ is $805 \mathrm{~m}$ and it is through $\mathrm{R}$.

\section{Conclusion}

Analysis of the shortest path of a proposed tramway for a potential world class University is carried out in this paper using the Dijkstra Algorithm. Covenant University is used as a case study. Some important spots on the campus are identified as the tramway stations. The Canaan land gate is using as the starting point, which represents the initial node $\mathrm{A}$ on the weighted graph in Figure 2. The last station is taking to be the Electrical Department, which represents our target node U. From the results obtained, it can be concluded that the shortest distance between the Canaan land gate and the department of Electrical Engineering is 805 meters. This has to be put into consideration during construction of the tramway so as to cut cost and save time of the users of the tram, as a result of the shortest route identified in this study.

\section{References}

[1] Badawy, E.D. and Sargent, J.E. (2000) Trams and Streetscapes Metropolitan Melbourne 1950s-1960s: A Photographic Profile. 4th Edition, Train Hobby Publications, Melbourne, 1.

[2] Agarana, M.C. and Gbadeyan, J.A. (2015) Finite Difference Dynamic Analysis of Railway Bridges Supported by Pasternak Foundation under Uniform Partially Distributed Moving Railway Vehicle. International Conference on Systems Engineering and Engineering Management (IAENG), San Francisco, 21-23 October 2015, 996-1000.

[3] Morrison, A. (2013) The Tramways of Bogota Colombia, Electric Transport in Latin America.

[4] Thorup, M. (2000) On RAM priority Queues. SIAM Journal on Computing, 30, 86-109. http://dx.doi.org/10.1137/S0097539795288246

[5] Tram-Definition and More from the Free Merriam Webster Dictionary (n.d.).

[6] Urban Rail Transit; from Wikipedia, the Free Encyclopedia. https://en.wikipedia.org/wiki/Urban_rail_transit

[7] Ahuja, R.K., Mehlhorn, K., Orlin, J.B. and Tarjan, R.E. (1990) Faster Algorithms for the Shortest Path Problem. Journal of Association for Computing Machinery, 37, 213-223. http://dx.doi.org/10.1145/77600.77615

[8] Thorup, M. (1999) Undirected Single-Source Shortest Paths with Positive Integer Weights in Linear Time. Journal of the ACM, 46, 362-394. http://dx.doi.org/10.1145/316542.316548

[9] Santitham Prom-on (2013) Finding the Shortest Path Using Dijkstra's Algorithm. King Mongkut's University of Techology, Thonburi.

[10] Sunanda, D. and Pramod, P. (n.d.). Railway Route Optimization System Using Dijkstra Method. International Journal on Recent and Innovation Trends in Computing and Communication, 2, 3435-3440.

[11] Dijkstra's Algorithm from Wikipedia, the Free Encyclopedia

[12] www.shutterstock.com/s/tram/sear.html

[13] Agarana, M.C. and Olokunde, T.O. (2015) Optimization of Healthcare Pathways in Covenant University Health Centre using Linear Programing Model. Far East Journal of Applied Mathematics, 91, 215-228.

[14] Guglielminetti, J.-P.L. (2001) Freight Transport Planning: An Optimisation Model for the Swiss Transport Research Conference. Institute of Transportation and Planning (ITEP), 1-3. 